CUADERNOS DE ESTUDIOS GALLEGOS, LVIII N. ${ }^{\circ}$ 124, enero-diciembre (2011), pp. 253-274

ISSN 0210-847 X

\title{
EL GRAN PROYECTO DE ANTONIO BERMEJO Y ARTEAGA PARA SANTIAGO DE COMPOSTELA: LA ESCUELA DE VETERINARIA COMO ÉMULA DE LA ÉCOLE D'ANATOMIE D'ALFORT EN PARÍS
}

Iván Moure Pazos

Universidad de Bolonia - Fundación Pedro Barrié de la Maza 


\title{
EL GRAN PROYECTO DE ANTONIO BERMEJO Y ARTEAGA PARA SANTIAGO DE COMPOSTELA: LA ESCUELA DE VETERINARIA COMO ÉMULA DE LA ÉCOLE D'ANATOMIE D'ALFORT EN PARÍS
}

\begin{abstract}
RESUMEN
Bajo el promotorado de D. Eugenio Montero Ríos, tendrá lugar en Compostela una renovación de carácter arquitectónico y educativo que afectará a la nueva imagen de la ciudad finisecular. Entre las intervenciones de más calado se cuenta La Escuela de Veterinaria (actual Parlamento de Galicia), creada por Antonio Bermejo y Arteaga a imagen y semejanza de L'École d'Anatomie d'Alfort de Diet en París.
\end{abstract}

Palabras ClaVe: Eugenio Montero Ríos, Santiago de Compostela, Escuela Veterinaria, Arquitectura Ecléctica.

\section{THE ANTONIO BERMEJO Y ARTEAGA'S GREAT PROJECT FOR SANTIAGO DE COMPOSTELA: THE SCHOOL OF VETERINARY AS EMULATOR OF ÉCOLE D'ANATOMIE D'ALFORT IN PARIS}

\begin{abstract}
Under Mr. Eugenio Montero Rios' promotion, an architectonical and educational renovation will take place in Compostela, which will affect to the town's image at the end of the $19^{\text {th }}$ century. One of the most relevant interventions will be the Veterinary School (current Galician Parliament), projected by Antonio Bermejo y Arteaga as the image and likeness of the Parisian École d'Anatomie d'Alfort of Diet.
\end{abstract}

KeY WORDS: Eugenio Montero Ríos, Santiago de Compostela, Veterinary School, Eclectic Architecture. 
Recibido/Received: 08/07/2010

Aceptado/Accepted: 27/07/2011

\section{INTRODUCCIÓN}

$\mathrm{E}$

NTRE el último cuarto del siglo XIX, y principios del XX, Galicia seguía siendo una comunidad eminentemente agraria caracterizada por una escasa industria, a la par que era una de las zonas de España con mayor densidad poblacional ubicada en núcleos dispersos de aglomeración demográfica. Debido al gran paro imperante en las áreas rurales, pronto se optará por una errada migración masiva a las ciudades, donde muchos no encontrarían en ellas más que decepción y desempleo, hecho que, de manera forzosa, desembocará -en el mayor de lo casos- en emigración ${ }^{1}$. Pero si difícil era la situación gallega, más lo sería la triste realidad santiaguesa, ya que la pretendida modernización industrial, bien fuese conservera, naval, o agroindustrial, parecía mostrarse ajena a una preferencia compostelana, afirmándose por la contra en otros núcleos poblacionales como A Coruña, Ferrol, o Vigo. Por lo tanto, y en base a una acuciante falta de industrialización, Santiago comenzará a autodefinirse como una ciudad señera en lo educativo y en lo religioso ${ }^{2}$, donde si bien pudiésemos argumentar que se verá afectada por un estancamiento económico derivado de su congelamiento demográfico ${ }^{3}$, lo cierto es que, paradójicamente, en ella se llevarán a cabo una serie de importantes reformas arquitectónicas y urbanísticas que en mucho contribuirán a la estabilización de Compostela como

\footnotetext{
${ }^{1}$ BONET CORREA, Antonio, "Las ciudades gallegas en el siglo XIX", Arte y Ciudad. Ámbitos medieval, moderno y contemporáneo, Santiago de Compostela 2000, 180.

2 R. VILLARES, "La ciudad de los dos Apóstoles (1875-1936)", Historia de la Ciudad de Santiago de Compostela, Santiago de Compostela 2003, 478.

3 Ibid, 481. "La principal característica que define la situación demográfica de la ciudad compostelana, desde mediados del siglo XIX hasta bien entrado el siglo XX, es la estabilidad de sus efectivos, comportamiento que ha merecido calificativos como de aciago siglo XIX o de Anodino crecimiento poblacional. Con una población de 23.773 habitantes en 1860 (en la que se incluye todo el municipio), en el censo de 1920 el recuento de sus habitantes alcanza la cifra de 25.870 , lo que supone que en el trecho de sesenta años la población compostelana apenas había crecido un ocho por ciento".
} 


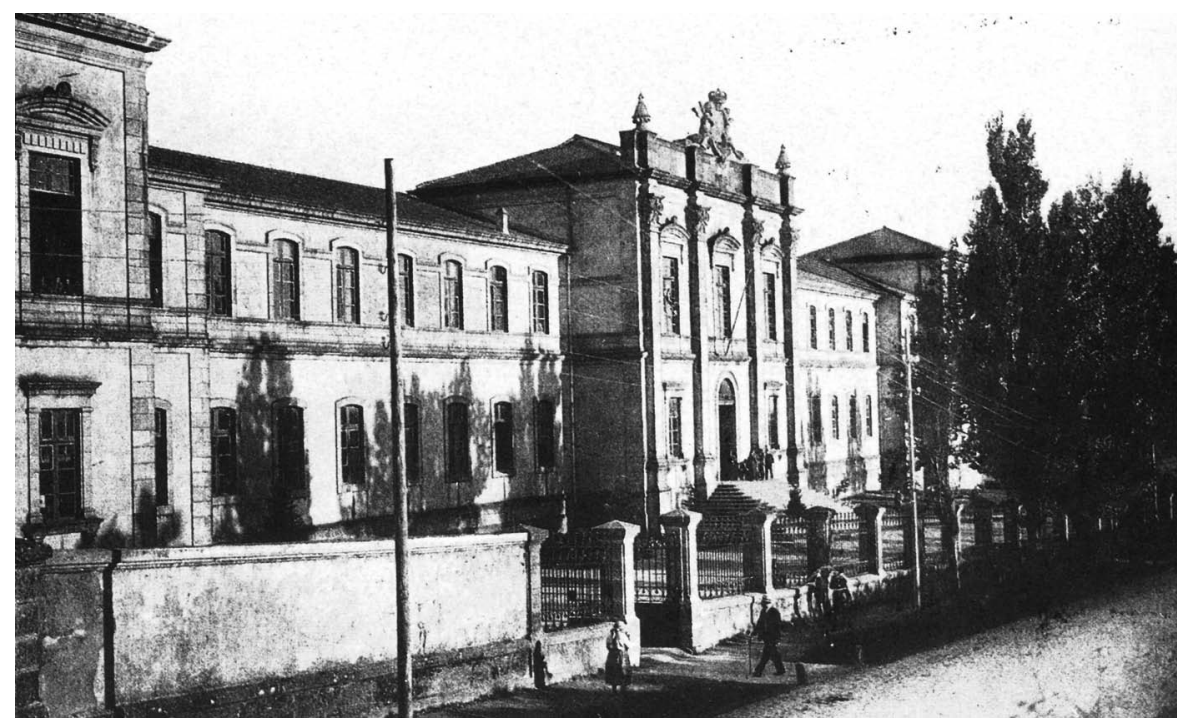

Fig. 1

Antonio Bermejo y Arteaga. Escuela de Veterinaria. 1915. Col. Biblioteca Xeral de la USC

indiscutible centro del saber. Entre las más señeras, y sin menoscabo de la espectacular Escuela de Medicina (1928) creada por Fernando Arbós y Tremanti, se cuenta la olvidada Escuela de Veterinaria (1915) (actual parlamento Gallego) proyectada por Antoinio Bermejo y Arteaga, y auspiciada en todo momento por el augusto benefactor Don Eugenio Montero Ríos, que desde sus altos cargos en el gobierno de la nación impulsó a lo largo de toda su vida cualquier medida que beneficiase a la susodicha institución [fig. 1].

EL PROYECTO DE ANTONIO BERMEJO Y ARTEAGA: TAXONOMÍA ESPACIAL Y MEMORIA EDILICIA

"Para que el pueblo de Santiago se pueda formar una idea completa de la grandiosidad de este edificio, y por consecuencia, de la importancia del obsequio que le ha hecho el ilustre señor Don Montero Ríos, lo vamos a comparar con otros que sean conocidos por todos, de lo cual resulta ser más del doble que San Clemente y tener 32 metros de más de fachada que nuestro monumental Consistorio, siendo el doble de ancho que éste"4.

${ }^{4}$ La Voz de Galicia (25-03-1903). 
Acaso le debamos a las palabras de Ramón García Suárez, presidente de la junta de obras, el que, de una manera introductoria, nos pongan sobre los precedentes de lo que este vasto proyecto arquitectónico supuso para una modesta ciudad como Santiago de Compostela. Proyecto que, sabemos, fue realizado por Antonio Bermejo y Arteaga y continuado, tras su muerte, por Arturo Calvo, quien se hace cargo del proyecto modificando algunos aspectos básicamente ornamentales de la propuesta inicial, manteniendo la división espacial, planta, y estructura arquitectónica del proyecto originario.

Una vez aclaradas algunas autorías, veamos, pues, la distribución del complejo [fig. 2]. Este se extendería por un total de 59.859 metros cuadrados, de los cuales, el arquitecto dedicó 5.830 para la edificación y 54.026 para patios, jardín botánico, y granja experimental ${ }^{\mathbf{5}}$. Insertos en dichos terrenos, el arquitecto acuerda proyectar 5 edificios en función de las necesidades de la escuela, meticulosamente descritos por Ramón García y Suárez:

El principal ó verdadera escuela con dos plantas ó pisos y cuatro pabellones pequeños de planta baja situados detrás y á bastante distancia de aquel y destinados dos de ellos á clínicas de enfermedades contagiosas, uno á herradero y fragua y otro á baño para los grandes solípedos y rumiantes. Las dimensiones de cada uno de los pabellones destinados a clínicas de enfermedades contagiosas son de 16 metros de largo por 8 de ancho y están divididos interiormente en dos departamentos con el objeto de que haya aislamiento completo entre los animales enfermos. El pabellón destinado á fragua mide 22 metros de largo por 17 de ancho y se compone de dos galerías destinadas a herradero, de un salón central con 8 fraguas para las prácticas de forjado, de un despacho para el profesor de estas enseñanzas y de dos almacenes para combustibles, teniendo en los ángulos de su fachada posterior dos depósitos de agua con una capacidad en conjunto de 128.000 litros y al lado la máquina de vapor elevadora de la misma. El pabellón destinado al baño tiene 22 metros de largo por 16 de ancho y le rodea por tres de sus lados una galería cubierta para abrigo y secadero de los bañistas y por último el pabellón principal o verdadera Escuela que llama su atención por su sencillez y elegancia; está constituido por cuatro cuerpos angulares y dos centrales, uno en la fachada anterior y otro en la posterior, todos salientes y unidos entre sí por seis cuerpos intermedios de treinta metros de longitud y enlazados con los primeros por amplias galerías de comunicación. Este pabellón que estará situado a 20 metros de distancia de la verja que se extiende a lo largo y borde de la carretera y a 32 kilómetros de los muros laterales que encierran el solar tiene 116 metros de largo por 66 de ancho y 20 metros de alto, ocupando una superficie de 4.870 metros cuadrado 6 .

En cuanto a la distribución interior del edificio principal y obedeciendo a la información proporcionada por La voz de Galicia, la escuela en su la planta baja vendría a albergar: vestíbulo, conserjería, portería, departamento de alumnos de guardia, cocina general, departamento para mejoramiento de razas, guadarnés,

$\begin{array}{ll}5 & I d . \\ 6 & I d .\end{array}$ 
sala destinada a la consulta pública, departamento de hidroterapia, galerías de comunicación, depósitos de substancias alimenticias, palafreneros de servicio, seis cátedras o clínica médica, otros para clínica quirúrgica, cátedra de obstetricia, anfiteatro anatómico, antesala y botiquín, sala de disección, sala de operaciones con potros de suspensión, escalera principal, otra de servicio, retretes, y patio central.

En la planta alta: Salón de actos públicos, habitaciones del director, sala de profesores, dirección, antedespacho, secretaría y archivo, biblioteca, despacho de bibliotecario, laboratorio de trabajos bacteriológicos, ídem histología, departamento de maceraciones, departamento de alumnos pensionados, gabinete fisiológico, museo zootécnico, arsenal farmacológico, arsenal quirúrgico, despacho del director de trabajos anatómicos, museo de anatomía patológica, gabinete de física, laboratorio quirúrgico, cátedras, antecátedras, gabinete de historia natural, entradas, departamentos de bedeles, museo de agricultura y arsenal agrícola, galerías de comunicación, escalera principal, escalera de servicio, retretes, y almacén ${ }^{7}$.

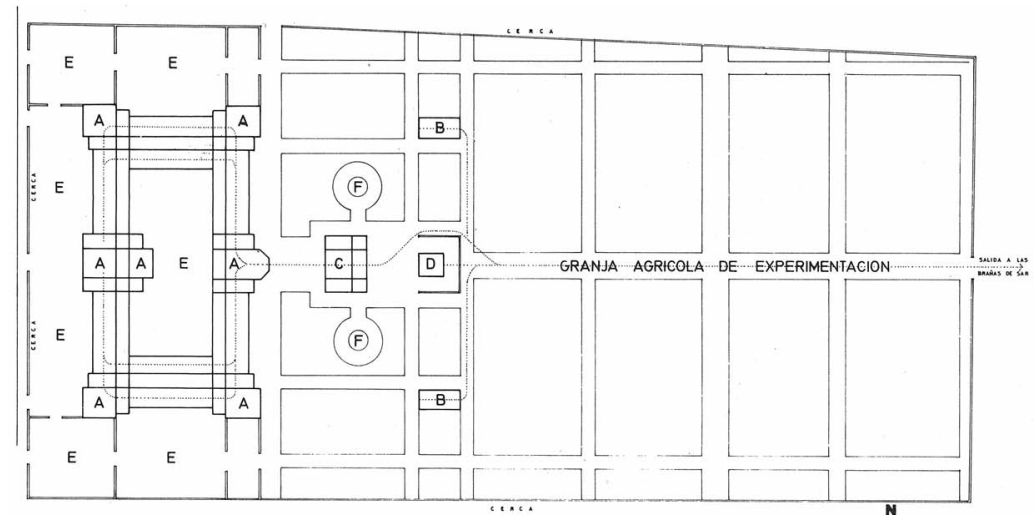

A) Edificio principal rodeado de patios al aire libre.

B) Dos pabellones de planta baja destinados a clínicas de enfermedades contagiosas.

C y F) Pabellón de planta baja destinado a herradero y fraguas, con dos máquinas elevatorias de agua a cada lado.

D) Pabellón de planta baja destinada a baño de rumiantes y grandes solípedos.

E) Patios

Fig. 2

Ordenación original de la parcela según los planos de distribución de Antonio Bermejo y Arteaga. 1903. Col. La Voz de Galicia (25-03-1903)

7 La Voz de Galicia (23-03-1903). 
EL PARADIGMA DEL ECLECTICISMO CLASICISTA: SECCIÓN HORIZONTAL DE UN EDIFICIO INSTITUCIONAL

A lo largo de la historia, no han sido pocos los teóricos que arguyeron que en el siglo XIX, el panorama arquitectónico Europeo se encontraba dominado por dos estilos aparentemente bien diferenciados: los diversos historicismos deudores de las formas arqueológicas pasadas, y el llamado eclecticismo basado en la hibridación de dichas formas ${ }^{8}$. En España, desde que Javier Hernando, hubiese definido a estos dos estilos como "dos voluntades, más que dos maneras de acometer el diseño arquitectónico”, largas y fructíferas empezarían a ser las nuevas disputas teóricas que vendrían a poner en duda el carácter autónomo de estos dos estilos. Si bien se pudiese afirmar que los historicismos obedecen a una interpretación cartesiana de los viejos modelos arquitectónicos, y que la visión ecléctica vendría a conjugar libremente estos modelos, lo cierto es que, esta dicotomía ya no se sustenta. La libertad interpretativa que los arquitectos historicistas infirieron a sus obras, a la manera ecléctica, es un hecho incontestable. Por otra parte, no considerar el eclecticismo como un revival historicista, se nos antojaría como el mayor de los errores. Por tanto, y parafraseando a Patetta, podríamos afirmar que "toda la arquitectura del XIX es ecléctica por su configuración e historicista por su base ideológica". Y es que, pese a lo que se suele argumentar, el historicismo ecléctico, seguirá viviendo de las mismas plantas y formas estructurales utilizadas por el neoclasicismo académico ${ }^{9}$, de lo que pudiera extraerse que su supuesta liberación tectónica no es tal, sino más bien, un lúdico juego ornamental que poco contribuirán a una ruptura con las estructuras dieciochescas ${ }^{10}$. Por consiguiente, no debiera extrañarnos que muchos autores omitan la calificación ecléctica, para seguir hablándonos de arquitectura neoclásica finisecular, aunque bien pudiese matizarse que el barroco superlativo de su ornamentación, en numerosas ocasiones fagocitará a la estructura clásica sobre la que se sustenta. Por lo tanto, aquellos edificios más representativos de un nuevo orden burgués, véanse teatros, óperas, o casas particulares, se armarán de profusas decoraciones que los significarán como edificios señeros de una acaudalada clase social. Por la contra, todas aquellas construcciones vinculadas a la institución, como hospitales, cárceles, bibliotecas, escuelas o ayuntamientos, seguirán decantándose por un estilo mayestático vinculado a la nobleza y el prestigio dieciochesco, provisto de una decoración

\footnotetext{
${ }^{8}$ BENITO GOERLICH, Daniel, La arquitectura del eclecticismo en Valencia, Valencia 1981, 31. 9 HERNANDO, Javier, Arquitectura en España (1770-1900), Madrid 1989, 386. "Cuando entre en crisis el neoclasicismo académico a partir del segundo tercio del siglo, ante el surgimiento de opciones alternativas al mismo, su pervivencia sólo será posible mediante una apertura ecléctica". ${ }^{10} \mathrm{Ibid}, 178$. "La aparente libertad ecléctica, resultante de la mezcolanza de estilos, no es más que un espejismo. Tras la profusa capa de columnas, capiteles, cornucopias, tomados del pasado, se oculta una composición tradicional".
} 
más templada y clásica, que en no pocas ocasiones, evolucionará hacia una desnudez absoluta de motivos ornamentales, donde como mucho se enfatizan líneas de imposta, basamentos, y cornisas sobre la neoclásica estructura soporte.

Es así como el eclecticismo clasicista, iniciará su andadura vinculado a un multitudinario elenco de edificios institucionales, de entre los que sobresaldrán las producciones escolares. Como es lógico, la escuela proyectada por Antonio Bermejo no se sustraerá a esta influencia académica, sino que por la contra, se constituirá como uno de los edificios más representativos del vástago ecléctico clasicista en territorio nacional.

Una vez aclaradas estas cuestiones preambulares, pasemos, pues, a analizar el proyecto original, que por otra parte, cabe recordarse, nunca llegó a realizarse de forma ortodoxa. Como ya especificamos en el precedente capítulo, la planta es rectangular, con un patio de igual forma, y con seis cuerpos en resalte, cuatro extremos y uno central correspondiente al alzado Oeste, y una antecátedra central perteneciente al cuerpo Este [fig. 3].

Esta obra pasará a engrosar la prolífica lista de edificaciones finiseculares que contribuirán al asentamiento de una vieja tipificación edilicia que, ahora más que nunca, será adoptada por hospitales, cárceles ${ }^{11}$, y escuelas, como pauta tectónica normativa al servicio de unas nuevas condiciones profilácticas y salubres, que de manera obligada, vendrían a exigir grandes espacios de oxigenación y circulación. Por ello, en lo cierto estaremos, si observamos el proyecto de la escuela desde un punto de vista de esterilidad médica, criterio que por otra parte, ya había condicionado la elección de un enclave periférico y alejado de la Compostela intramuros.

Pero si estas fueron las razones ideológicas imperantes que determinaron la construcción de la escuela, lo cierto es que, los arquitectos y teóricos neoclásicos ya habían aportado las resoluciones definitivas al modelo de estructuración ortogonal. Es por ello que Antonio Bermejo, al igual que el grueso de los autores decimonónicos, van a seguir inspirándose en la mismas fuentes y tratados que otrora configurasen el advenimiento neoclásico. Lícito será, pues, acercarnos a la tratadística que se verá representada de manera manifiesta en la obra que nos ocupa. Indefectiblemente, las obras de J. L. Durand, se constituirán como los ya consabidos manuales de uso de todo arquitecto decimonónico digno de aprecio ${ }^{12}$. En 1802, Durand catapultará los postulados neoclásicos con la publicación de lo que, con el tiempo, se convertirá en la Biblia arquitectónica del eclecticismo clasicista:

\footnotetext{
11 VIDLER, Anthony, El espacio de la ilustración. Madrid 1997, 114. El autor lleva a cabo un minucioso estudio sobre el desarrollo de esta tipología.

12 MIDDLETON, Robin - WATKIN, David, Arquitectura Moderna, Madrid 1979, 9.
} 

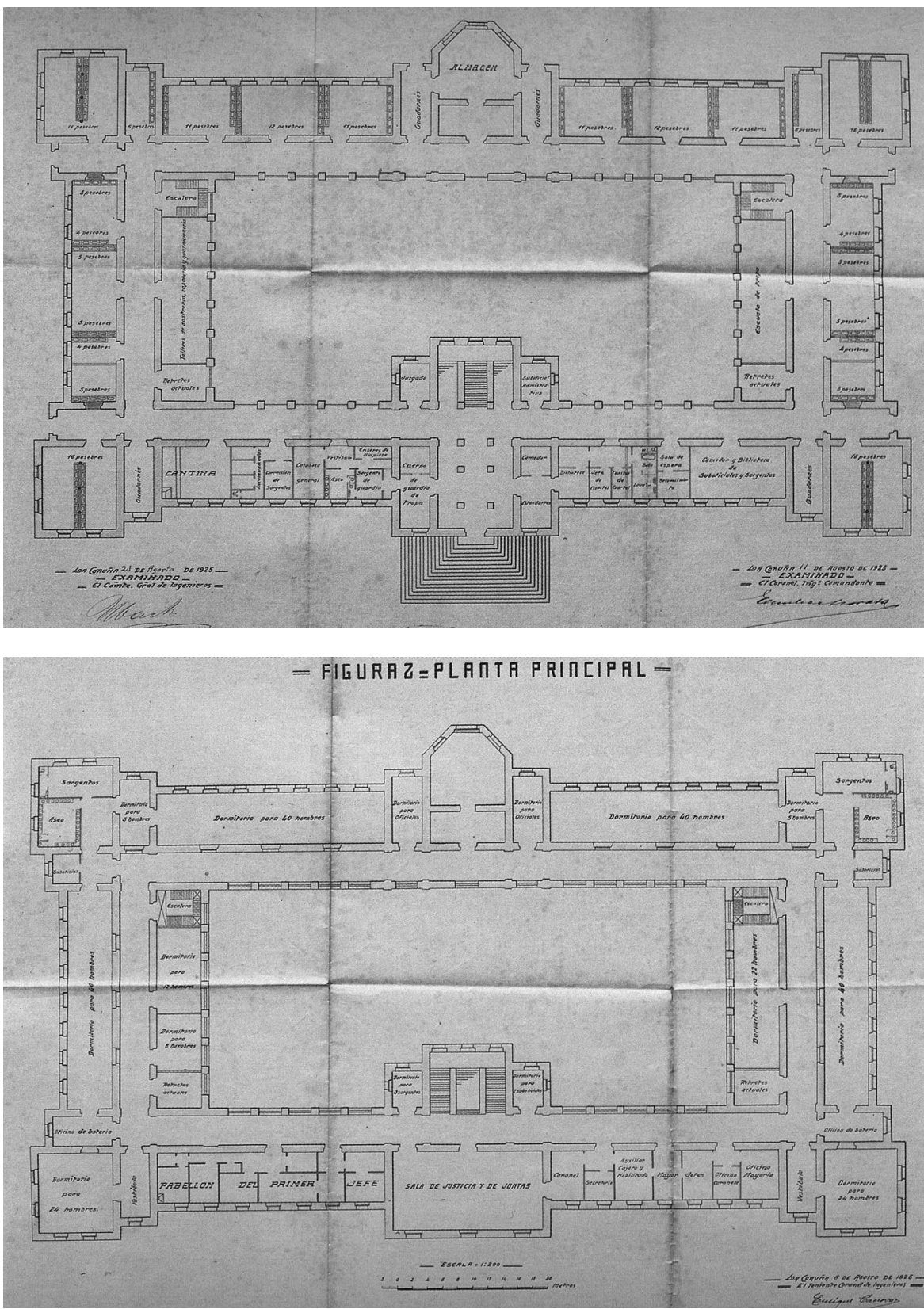

Fig. 3

Antonio Bermejo y Arteaga. Planta baja y superior de la Escuela Veterinaria de Santiago de Compostela. 1915. Col. Capitanía Xeral de A Coruña 
Précis des leçons d'architecture, domes á l"Ecole Polytechnique ${ }^{13}$. En dicho libro, se aboga por una serie de reduccionistas modelos arquitectónicos basados en la simetría, la yuxtaposición modular, o la biaxialidad a modo de cartesianos de sabor puramente racionalista, donde los ordenes dejarían de tener una presencia protagónica como elemento activador, para convertirse en pusilánime ornamentación ${ }^{14}$. Por consiguiente, la marcada ortogonalidad edilicia, derivará por defecto en la creación de volúmenes cúbicos, que comportarán la aparición de una tercera perpendicular, hecho que consumará en la infinitud de posibles dimensiones espaciales que permitirán al arquitecto jugar en planta con sustracción y adición de cuadrados tridimensional.

Es así como en la segunda mitad del siglo XIX, los tratados de Durand habían suscitado en gran parte de Europa el afloramiento de unas nuevas formas arquitectónicas austeras, así como una suerte de proliferación tratadística que irradiada por la École des Beaux-Arts de París, pronto encontrará a sus más fieles vástagos en las escuelas de arquitectura españolas, entre las que cabría reseñar a la Real Academia de Bellas Artes de San Fernando, aunque solo fuese porque allí, Antonio Bermejo se formara previamente a su asentamiento como arquitecto municipal en Santiago en $1876^{15}$. En dicha escuela, se familiarizaría no solo con los tratados oficiales, que a modo de manual contaba cada asignatura especifica del plan de estudios, sino con los numerosos y prolíficos tratados albergados en la rica biblioteca ${ }^{16}$, y que vendrían a constituirse como plantillas constructivas donde el arquitecto buscaba no solo inspiración, sino reglas precisas de construcción, que como veremos, condicionarán sobremanera la formación del profesional. En 1846 tiene lugar la publicación del Álbum de proyectos originales de arquitectura de Fornés y Gurrea, director de la academia de nobles artes de San Carlos de Valencia, quien a modo de álbum ilustrativo realizará un compendio arquitectónico estructurado por tipologías, para -según el autor- "facilitar el paso a la invención a los que se dedican a este noble arte". En él, se presenta un prototipo de planta para una casa de posadas para una capital, conjuntamente con una breve memoria descriptiva de todas las virtudes que debiera poseer dicho edificio; el cual bien pudiese valernos como uno de los precedentes de nuestra Escuela Veterinaria, puesto:

\footnotetext{
13 PICON, Antoine, Architectes et ingénieurs au siècle des lumières, Marsella 1988, 287.

14 VILLARI, Sergio, J.-N.-L. Durand (1760-1834), Arte e scienza dell'architettura, Roma 1987, 82-97.

15 COSTA BUJÁN, Pablo, "Documentación histórica", Concurso de anteproxectos para adaptación do cuartel do Hórreo para sede do Parlamento de Galicia, Santiago de Compostela 1987, 63. ${ }^{16}$ Hoy, en su mayoría, trasladados al fondo de la Escuela Técnica Superior de Arquitectura de Madrid.
} 
[...] que la hermosura de estos edificios más bien consisten en que todo esté con la debida propiedad, que en una bella arquitectura, debiendo su fachada principal tener el carácter propio y significativo de esta clase de edificios; por consiguiente su decoración arquitectónica consistirá en la sencilla de almohadillados, fajas y resaltes en sus ventanas; su entrada principal decorada sencillamente[...] Por fin, la mayor hermosura de estos edificios consiste, como se ha dicho, en la propiedad, buena ordenación, comodidad [...] La solidez que han de tener estos edificios está al alcance de todos, porque el continuo uso de las escaleras, patios, habitaciones, cuadras, etc., reclaman una construcción perfecta, tanto en cuanto á los materiales como en el modo de gastarlos, evitando de este modo los continuos reparos y remiendos en perjuicio de los propietarios. Por lo mismo, debiendo ser los cimientos sólidos y anchos, los basamentos interiores y exteriores y puerta principal, serán de piedra labrada de la mejor especie que se encuentre ${ }^{17}$.

Pero si cierto fue que toda la cultura académica fue esculpiendo de manera costante la formación del arquitecto, lo cierto es que trece años antes al encargo de su Escuela Veterinaria, se erigiría en suelo francés un edificio institucional, llamado a ser la fuente de inspiración más directa en la que se basará el arquitecto para acometer su obra futura, L'École d'Anatomie d'Alfort.

A finales del XIX, de las cinco escuelas veterinarias establecidas en España, sólo la de Santiago vendría a ubicarse en un edificio de nueva planta, circunstancia que vendría a laurear a dicha ciudad como la primera en territorio nacional poseedora de una escuela de veterinaria creada ex profeso. Hecho, que -amén de toda la formación teórica y práctica de la que Bermejo se había nutrido, y pese a contar en suelo español con tipologías arquitectónicas tremendamente afines a lo que sería su proyecto final- derivará en la búsqueda de un referente extranjero, que a modo de modelo, viniera a inspirar la construcción de la escuela santiaguesa. Como es lógico, dicho referente lo encontrará en París, concretamente en la Escuela Veterinaria de Maison-Alfort ${ }^{18}$. La escuela alfortiana, vendría a constituirse como la meca de la veterinaria internacional. En ella se llevaron a cabo importantes actuaciones arquitectónicas realizadas por los más afamados arquitectos a lo largo de sus más de tres siglos de existencia ${ }^{19}$. Varios serían los arquitectos que allí dejaron su impronta, destacándose a Soufflot, Desbruyeres, Goiffon, Cellerier, Convers, Jollier, Robelin, Robin, Bois, Peyre, Gilbert, o Diet, autor del Edificio Anatómico ${ }^{20}$ (1879-1882), en el que Antonio Bermejo se inspirará [fig. 4].

17 FORNÉS Y GURREA, Manuel, Álbum de proyectos de arquitectura, Madrid 1848, Capítulo V.

18 La Gaceta de Galicia (25-03-1903). "No hay para que decir que dado el laudable deseo de construir una escuela de Veterinaria modelo, que esté a la altura de la de Alfort de nuestra vecina República, con objeto de realizar en ella completas experiencias agrícolas y zootécnicas, y tener gran número de sementales de distintas especies y razas para mejorar la ganadería de la región".

19 Actualmente, todos los edificios construidos en el siglo XVIII y primera mitad del XIX se encuentran destruidos, siendo la escuela un producto de la arquitectura de fines del siglo XIX y XX. ${ }^{20}$ BERCHE, Claire, Archives de l'école nationale d'Alfort, Paris 1992, 1-33. 
EL RIGOR FORMAL: SECCIÓN VERTICAL DE UN EDIFICIO CUADRIFONTE.

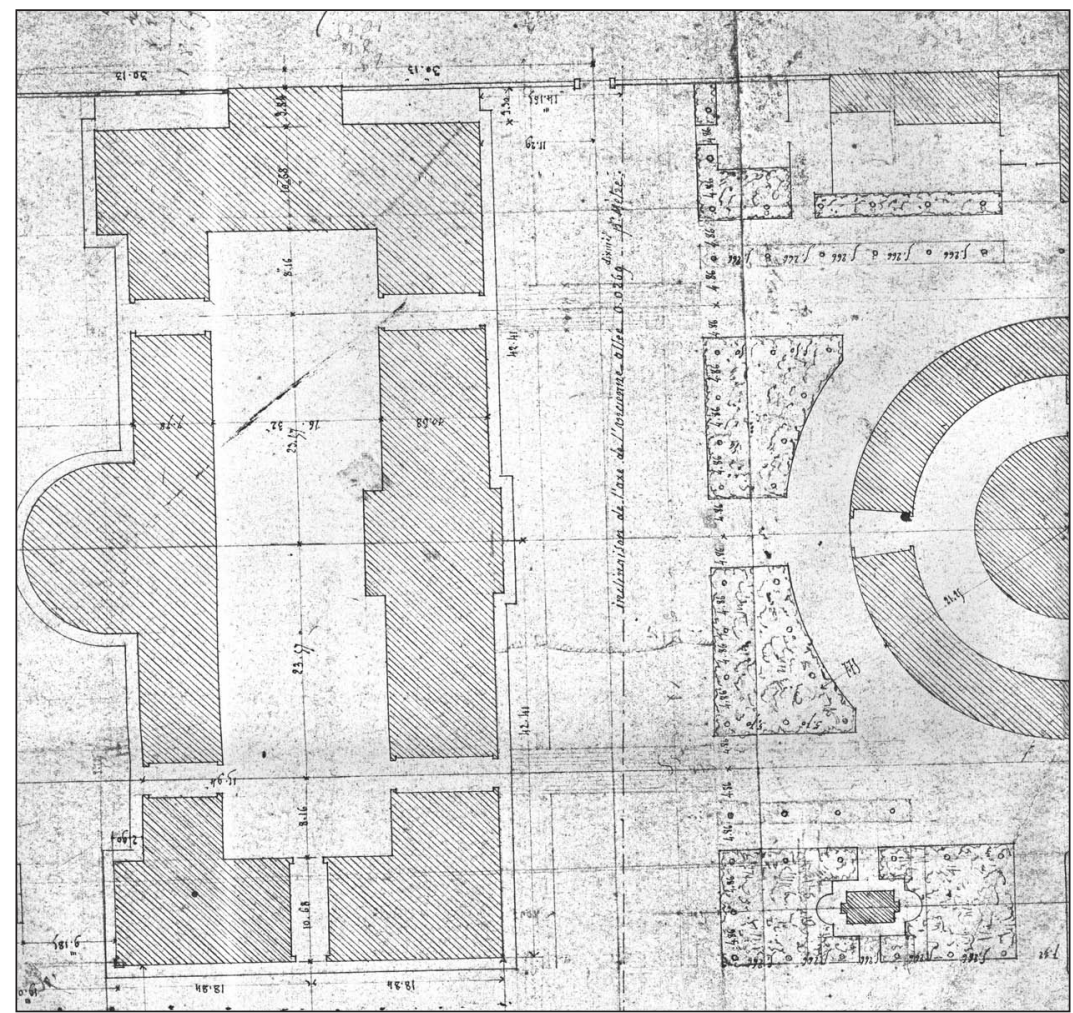

Fig. 4

Diet. Plano de L'École de Anatomie d'Alfort. 1882. Col. Archivos de L'École Nationale Vétérinaire d’Alfort (París)

De manera general, al analizar la sección vertical del edificio, no podemos sino corroborar las teorías expuestas en el capítulo precedente dedicado al estudio de la planta. Es así como conjuntamente al enorme patio central y los grandes espacios abiertos circundantes, la incesante multiplicación de vanos insertos en los muros carga, vendría a reiterarnos que nos encontramos ante un edificio que pretende ante todo la asepsia ${ }^{21}$, fuertemente vinculado a tipologías en común necesidad de esterilización espacial.

${ }^{21}$ Para más información relacionada con los sistemas de ventilación en la arquitectura del siglo XIX, se recomienda la consulta de DENFER, Jean, Fumisterie, Chauffage et ventilation, Paris 1889. 
Pero acerquémonos más al comportamiento del alzado exterior. A excepción del ábside Este y el cuerpo central de la fachada principal, las cuatro fachadas vendrían a organizarse de forma homogénea, basado no en el orden ornamental sino en el estructural, esto es, muros, paramentos, y pilastras adosadas que vendrían a perfilar la plomiza horizontalidad del edificio [fig. 5]. Sobriedad que se verá enfatizada en las seis crujías organizadas en dos alturas, donde los vanos como es común en los edificios ecléctico clasicistas- reciben un tratamiento decorativo diferente en función de la altura: en la planta baja sucesión de vanos escarzanos, en la superior ídem, pero esta vez unificados por impostas horizontales. Vanos, que serán inmortalizados por Sebastián Serlio en el libro cuarto de su tratado arquitectónico ${ }^{22}$-quien por otra parte cabe especificar, aportará a la ornamentación ecléctica lo que ya había proporcionado Durand al armazón estructural- y que en la segunda mitad del XIX, sin bien es cierto que nunca desaparecerá ${ }^{23}$, vivirá una especie de revival gracias a la divulgativa tratadística

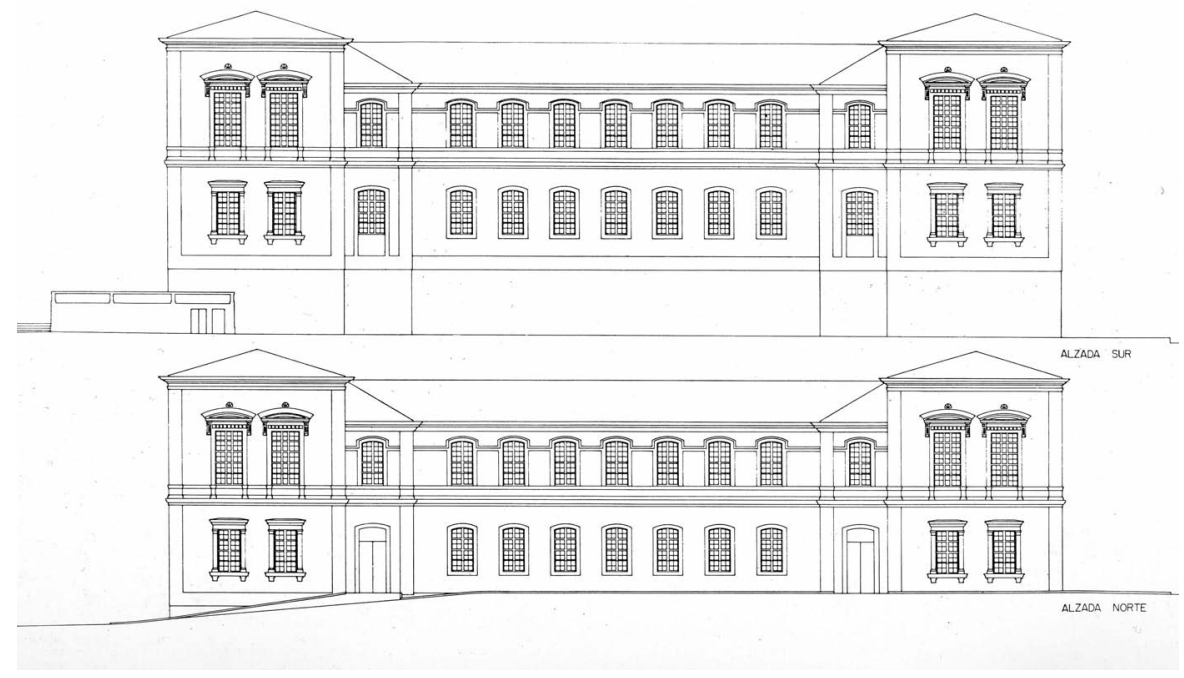

Fig. 5

Antonio Bermejo y Arteaga. Alzado Sur y Norte de la Escuela Veterinaria. 1915.

Col. J.F.F.-G.C.M

22 SERLIO, Sebastian, Tercer y cuarto libro de arquitectura, Toledo 1552, 13.

23 De hecho, una de las mejores documentaciones sobre el vano escarzano, la encontraremos en el siglo XVII, redactada por Fr. SAN NICOLÁS, en su tratado, Arte y uso de arquitectura, Madrid 1639, encontrado en los fondos documentales del archivo de la Escuela Técnica Superior de Arquitectura de Madrid, antaño ubicada en los fondos de la academia de Bellas Artes de San Fernando. En él, se lleva a cabo, paso a paso, el proceso de realización que se ha de seguir para la construcción de dicho vano. 
que señalará el escarzano ${ }^{24}$ como propio para aquellos edificios dotados de lacónica ornamentación, y sencillez estructural a la manera neoclásica.

Las crujías vendrían a rematar en respectivos cuerpos intersticiales adosados a los cuerpos angulares y ábside. En ellos, los vanos obedecerían al mismo tratamiento del cuerpo apaisado -a excepción del agrandamiento de los vanos inferiores en el alzado norte y sur-, pero aquí el autor rompe la horizontalidad del almohadillado introduciendo marbetes en las dos alturas que vendrían a reforzar la arista del retranqueado.

En cuanto a los cuerpos angulares, estos se constituyen en su parte baja por vanos adintelados, enmarcados por pilastras de riguroso dórico con remate acornisado; en el piso superior de nuevo vanos adintelados, pero esta vez, el arquitecto añade decoración denticulada de acortado metátomo, entre ménsulas sustentando un frontis semicircular coronado con antema de corte neorrenacentista. Formas nuevamente originarias del libro tercero y cuarto de Serlio ${ }^{25}$, donde inicialmente se vinculará el vano con frontis semicircular a la elegancia jónica, y que derivará en una suerte de eclecticismo formal, a la luz de los sucesivos tratados que lo irán enriqueciendo. Partiendo de los inmediatamente sucesivos libros de Vignola ${ }^{26}$ y Palladio $^{27}$, pasando por la barroca antología de Brizguz y $\mathrm{Bru}^{28}$, para finalizar con los innumerables tratados decimonónicos que, a tenor de un más que establecido historicismo neorrenacentista, innovará sobre la miscelánea vano-orden, de los cuales resaltaré Traité D'architecture de Léonce Reynaud ${ }^{29}$, Architecture et construction civiles. Maçonnerie de J. Denfer ${ }^{30}$, o el tratado de José Planella y Coromina, Arte de la perspectiva ${ }^{31}$.

El cuerpo principal, de estructura durandoniana ${ }^{32}$, vendría a comportarse igual que los angulares, solo que aquí al introducirse la puerta principal se suma un vano al cuerpo superior entre los espacios interpilastrados, coronado por un friso rotulado con antemas vegetales en remate [fig. 6].

\footnotetext{
24 Prácticamente, toda la tratadística del XIX dedicará un pequeño apartado a este vano. Valga como ejemplo: PORTUONDO, Bernardo, Lecciones de arquitectura, Madrid 1877, del que la academia de Bellas Artes de San Fernando poseía una copia, y que se convirtió en uno de los manuales a seguir por todos los arquitectos del momento.

25 SERLIO, Sebastian, op. cit., 25.

26 VIGNOLA, Jacopo, Regla de los cinco ordenes de arquitectura, Madrid 1593, 42.

27 PALLADIO, Andrea, Los cuatro libros de arquitectura, Madrid 1797, 17.

28 BRIGUZ Y BRU, Anastasio, Escuela de arquitectura civil, Valencia 1738, 90-3.

29 REYNAUD, Léonce, Traité D'architecture, Paris 1860, 32-4.

30 DENFER, Jean, Architecture et construction civiles. Maçonnerie, Paris 1891, 316.

31 PLANELLA Y COROMINA, Josep, Arte de la perspectiva, Barcelona 1840, 38.

32 PICON, Antoine, op. cit., 287.
} 


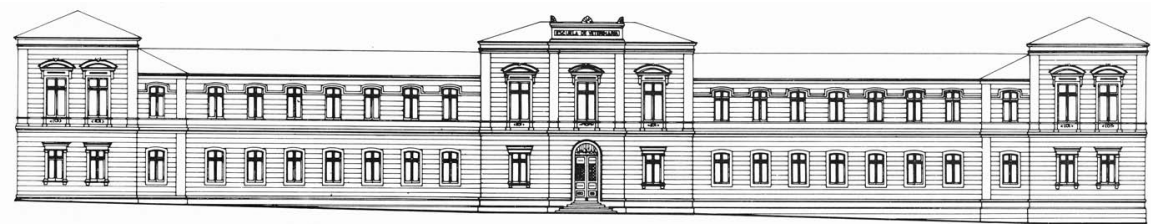

Fig. 6

Antonio Bermejo y Arteaga. Alzado de la fachada principal. 1915. Col. La Voz de Galicia (25-03-1903)

El ábside, se constituirá como el único cuerpo del conjunto ajeno a una estructuración cúbica [fig. 7]. Sin embargo, cabe matizar que el autor no opta por un hemiciclo semicircular al modo alfortiano, sino que pese a todo, crea un ábside aristado pentalateral remarcado por marbetes de orden gigante, que consumará en la desaparición de la cornisa de cincha que venía diseccionando todo el perímetro parietal en dos alturas. Ábside, que pese a su aparente originalidad, ya había sido ensayado en la facultad de ciencias madrileña ${ }^{33}$ proyectada por Eduardo Saavedra en 1889.

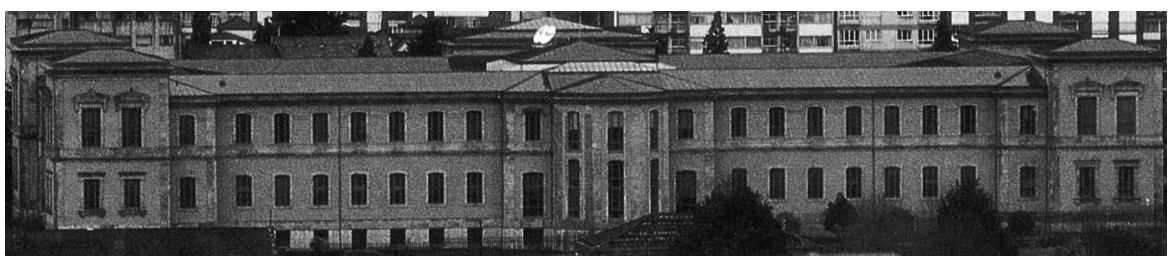

Fig. 7

Antonio Bermejo y Arteaga. Alzado Este de la Escuela de Veterinaria santiaguesa. 1915.

Col. Juan Rodríguez

El alzado del gran patio interior ${ }^{34}$ se organizaría de forma homogénea a excepción del sobresaliente cuerpo principal y de la utilización del orden gigante en el lateral Este. En base a dos alturas con imposta y cornisa, con sucesión de vanos monóforos de tercio punto sobre jambaje dórico en la zona baja, y estructura dintelar con pilastras dóricas en el piso superior. Tipología claustral que, de nuevo, nos llevaría a l'École d'Anatomie d'Alfort, con la salvedad de que Antonio Bermejo transforma la sucesión de arcos de medio punto en elegantes escarzanos, por otra parte, afines a los proyectados en el alzado exterior [fig. 8].

33 BALDELlOU SANTOLARIA, Miguel Ángel, Ricardo Velázquez Bosco, Madrid 1990, 273-74.

34 Actualmente, el patio rectangular se encuentra dividido en dos. Esto debido a la instalación del salón de sesiones del Parlamento Gallego. 


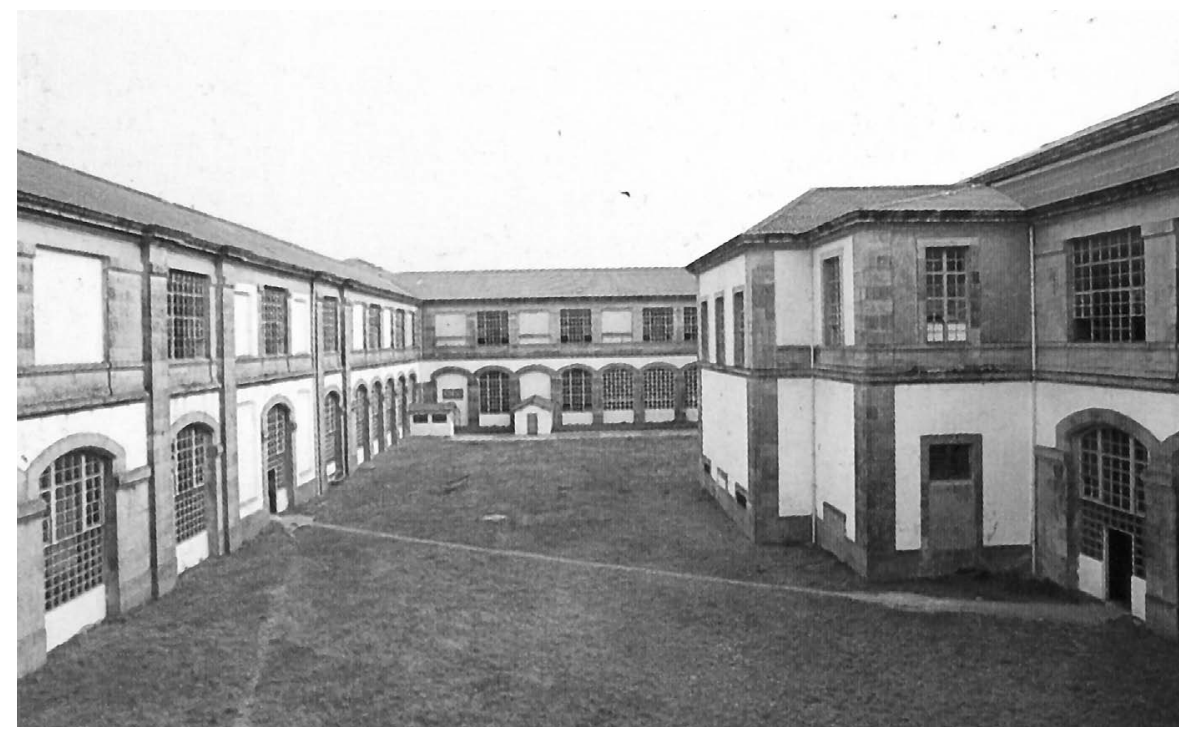

Fig. 8

Antonio Bermejo y Arteaga. Patio de la Escuela Veterinaria de Santiago. 1915. Col. Juan Rodríguez

Para finalizar, y como es propio en el llamado siglo del hierro, delimitará la célula edilicia un enorme cercado con puerta de doble batiente -actualmente depositado en los sótanos del edificio- realizado en varilla de hierro de sección cuadrada y circular en juego mixtilíneo de volutas y discos inscritos en una malla ortogonal rematada en flechones prismáticos con chambilla, al más puro estilo francés [fig. 9]. Formas, por supuesto, surgidas a la luz de las nuevas afinaciones y galvanizados ferruginosos ${ }^{35}$, de los que se hará eco la novedosa tratadística ar-

35 ROVIRA I RABASSA, Antoni, El hierro sus cortes y enlaces, Barcelona 1900, 155-56. "La metalurgia del hierro hace escasamente un siglo, se valía de métodos empíricos; entonces las buenas cualidades del metal, parecían depender de la riqueza de los minerales que lo contenían, y así se extraía de los minerales anhidros diseminados en filones, tales como el hierro espático (carbonato de hierro), el hierro oligisto, la ematita roja (sesquióxido de hierro), el óxido magnético por el que se obtienen los aceros. Mas desde el momento que la ciencia hubo proporcionado y facilitado largamente la afinación del metal, sea cual fuese su procedencia para con respecto al mineral que lo envuelve, entonces pudieron explotarse, con ventaja los minerales hidratados, dispuestos por capas en los terrenos sedimentarios, su explotación produjo cantidades considerables del mineral y con ellas se pudo dar cumplimiento, á las nuevas y continuas necesidades que se iban creando, con la serie de inventos industriales, siendo unas consecuencia y como hijas de las otras; mas por otra parte, no escaseando ya el metal, como sucedía en épocas anteriores, y derramándolo en prodigiosa cantidad, las inmensas producciones que salen de los altos hornos y de los de afinación, ha hecho que aparezca en los mercados a precios relativamente económicos [...] de aquí que éste venga á ser un importante elemento preferido por su bondad, duración y economía...". 
quitectónica, que ahora no solo introducirá como elementos indispensables las nuevas formas del hierro artístico, sino que surgirán tratados específicos exclusivamente dedicados al estudio del material y sus posibles usos ${ }^{36}$.

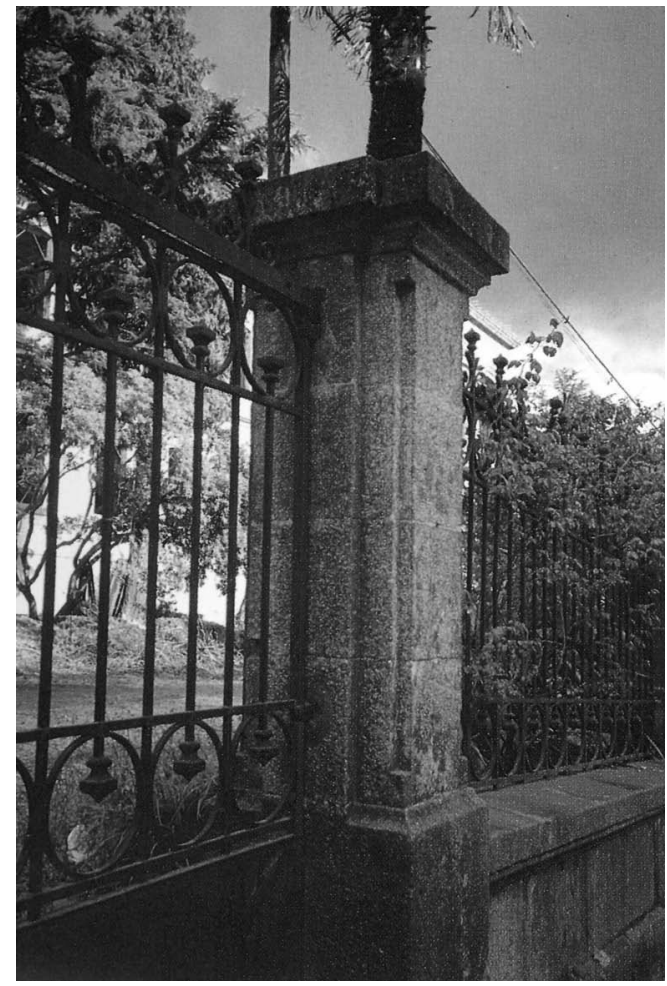

Fig. 9

Antonio Bermejo y Arteaga. Detalle de la verja. 1915. Col. Juan Rodríguez

LA REFORMA dE ARTuRo CALVO: unA VISIÓN ORNAMENTADA DE LA FACHADA OESTE.

En 1903 se llevará a cabo una variación del proyecto original de la mano del arquitecto y también director de obras Arturo Calvo, ya conocido en Compostela por el proyecto presentado para la restauración del edificio de San Jerómino, así

36 Ibid, 157. Pondrá en relación el uso del hierro con la higiene: "La higiene prescribe que en las grandes urbes, se disemine en gran cantidad, mucho aire, mucho luz, elementos principales de la vida, y eso no solo para los departamentos destinados á aglomerarse gran número de individuos, como son los hospitales, cuarteles, cárceles...etc, sino que también en las habitaciones particulares". 
como por las obras de la universidad santiaguesa ${ }^{37}$. Éste, modificará la propuesta inicial circunscrita básicamente al cuerpo principal, unificando las dos alturas principales en base a cuatro pilastras de orden gigante a modo palladiano ${ }^{38}$, toda vez conserva el interpilastrado originario [fig. 10]. Solución, muy común en los edificios institucionales de época que será acogida por el grueso de las escuelas veterinarias Europeas ${ }^{39}$, de entre las que quizás quepa resaltarse por su elegancia y porte a la Escuela de Veterinaria de Praga, la cual, aplicará dicho orden también a sus cuerpos extremos.

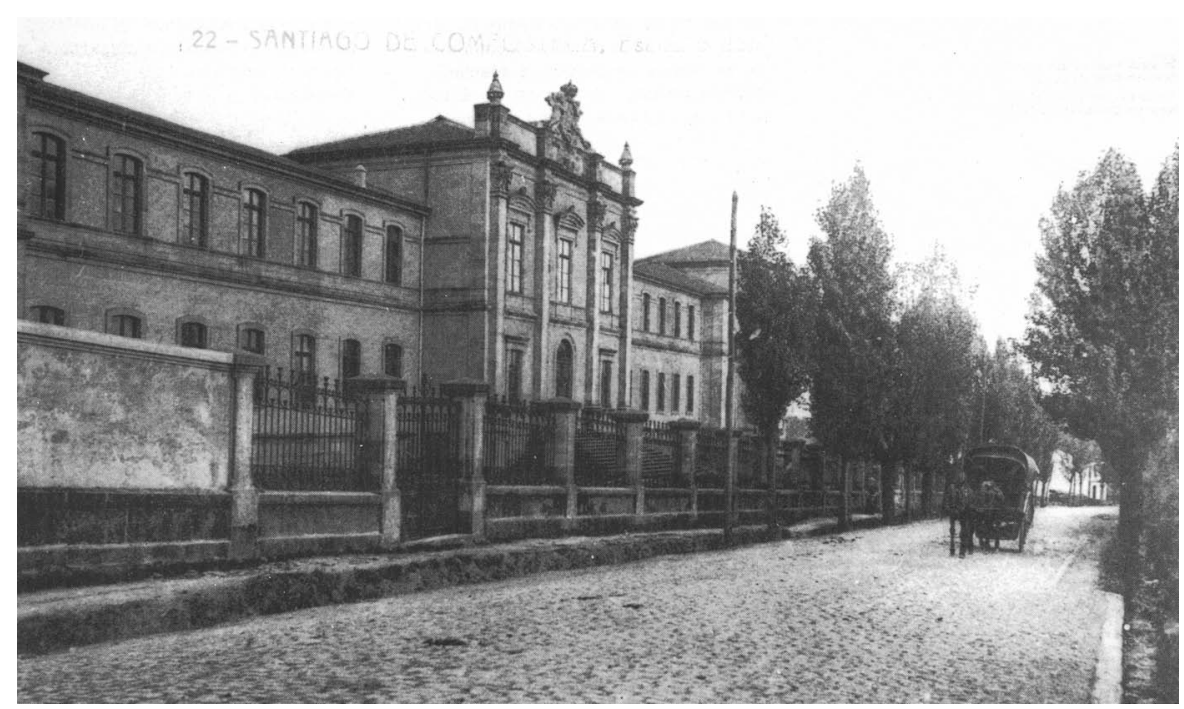

Fig. 10

Arturo Calvo. Escuela Veterinaria compostelana. 1915. Col. Eugenio de la Riva

Pero si de poco original podríamos calificar la solución del arquitecto, no se podrá decir lo mismo del diseño de los capiteles de dichas pilastras. Y es que, como es usual en el arquitecto histórico-ecléctico, se llevará a cabo una versión propia de los órdenes arquitectónicos. En este caso, Arturo Calvo realizará una original reinterpretación sobre la hibridación del jónico de cuatro caras y el co-

\footnotetext{
37 La Gaceta de Galicia. (25-03-1903).

38 PALLADIO, Andrea, op. cit., 12.

39 A falta de referentes nacionales, será usual vincular la escuela con otros referentes europeos de nueva planta con los que, cabe especificarse -a excepción de Alfort y la escuela de Praga- nada tendrán que ver. Me estoy refiriendo a las mencionadas por La Gaceta de Galicia el 01-10-1915. “[...] Magnífico edificio, que alguno podrá igualar con las escuelas de Bruselas, Munich y Budapest $[\ldots] "$.
} 
rintio, o lo que es lo mismo, del orden compuesto [fig. 11] ${ }^{40}$. El capitel se divide en dos franjas delimitadas por un remarque semicircular. En la parte baja el autor duplica el único baquetón sobre el que descansa el capitel compuesto con sendos listeles separados por un collarino decorado por sucesión de discos. Sobre ellos,

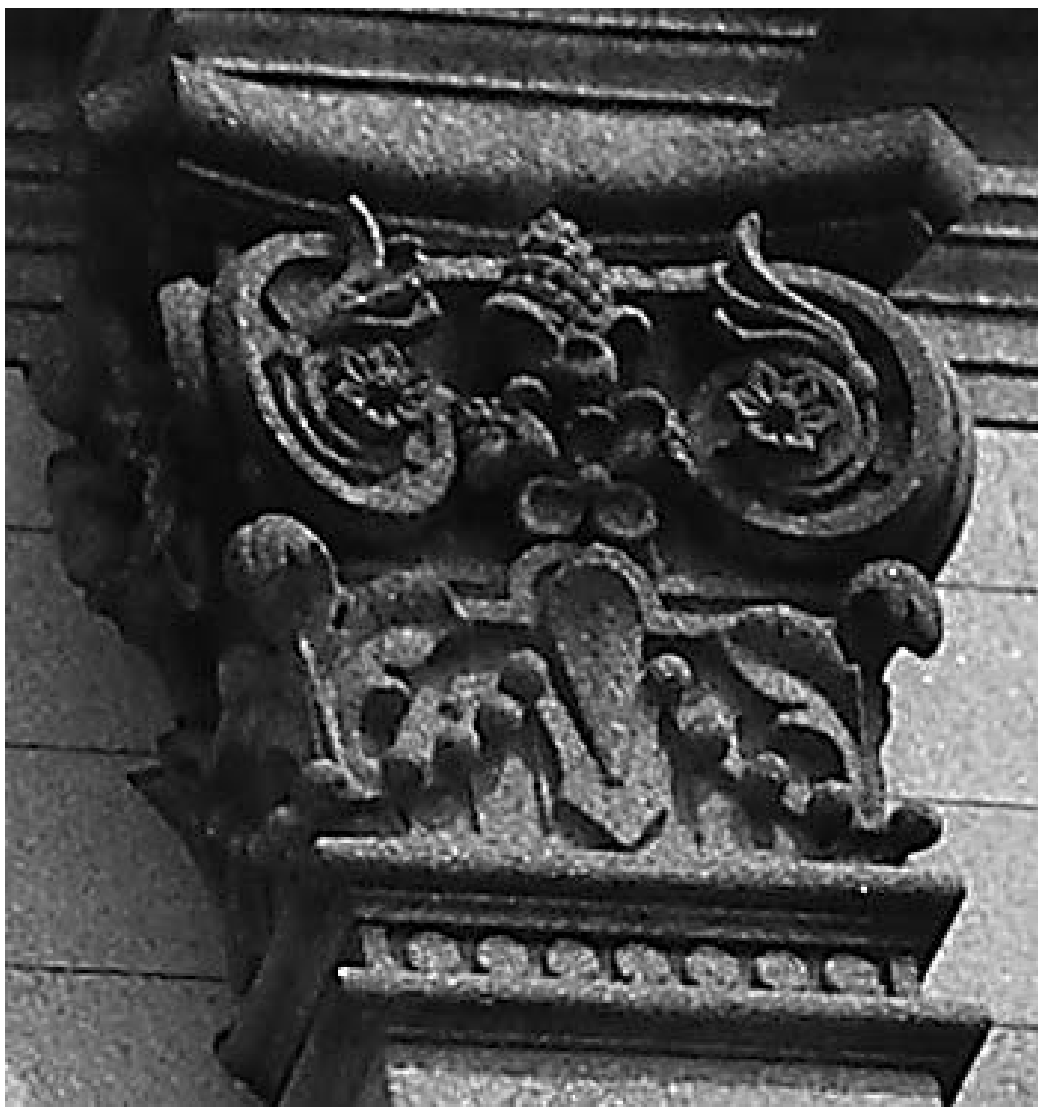

Fig. 11

Arturo Calvo. Capitel de la escuela veterinaria compostelana. 1915. Col. Autor

${ }^{40}$ El capitel compuesto fue una invención romana, posiblemente nacida en los últimos años de la República y desarrollada totalmente antes de la muerte de Augusto. El empleo más antiguo que ha podido registrarse del uso del orden compuesto data del año $82 \mathrm{~d}$. C., en el arco de Tito, presumiblemente después de la muerte de Vitrubio, ya que este último jamás menciona esta enriquecida hibridación. 
y superpuestos a un fondo estriado, simplifica las dos coronas de acantos propias del compuesto en una, relegadas a las zonas angulares a modo trihojal, siendo ocupada la parte central por un pétalo en resalte del cual nace un rosario perlado que recorre las tres caras del capitel. En la parte superior, se reduce la altura del rosetón del ábaco que pasa a ocupar la zona central del capitel, coronada por una piña a modo de rosa corintia. En los cuerpos angulares, volutas de ancho caulículo, pero aquí el autor introduce lotos que emanan del óculo con sus respectivas semipalmetas jónicas bajo un ábaco compuesto.

Por otra parte, la nueva disposición exigirá tanto la adición de una nueva escalinata, como el levantamiento de un desmedido ático decorado por bolas de coronamiento en extremos, con un gran grupo escultórico central conformado por un escudo nacional ${ }^{41}$ sustentado por sendos angelotes, obra de Rafael de la Torre Mirón, quien realizará la obra en base a diferentes materiales como restos de ladrillo, mortero de cemento, o vaciados sobre molde de yeso para las partes más comprometidas, como las cabezas, el escudo o las guirnaldas [fig. 12]. Y del que, en palabras de Andrés Reboredo Santos:

la altura y la pátina de meteorización, enmascaraban la realidad de una obra de muy baja calidad, que no cabe clasificar como escultura,- y sigue-Se intentó despedazar el conjunto para reconstruirlo en el jardín, más como una referencia anecdótica que por voluntad conservacionista. La heterogeneidad de su masa, cascote, mortero y armaduras hizo imposible este intento, en el que a veces se despren-

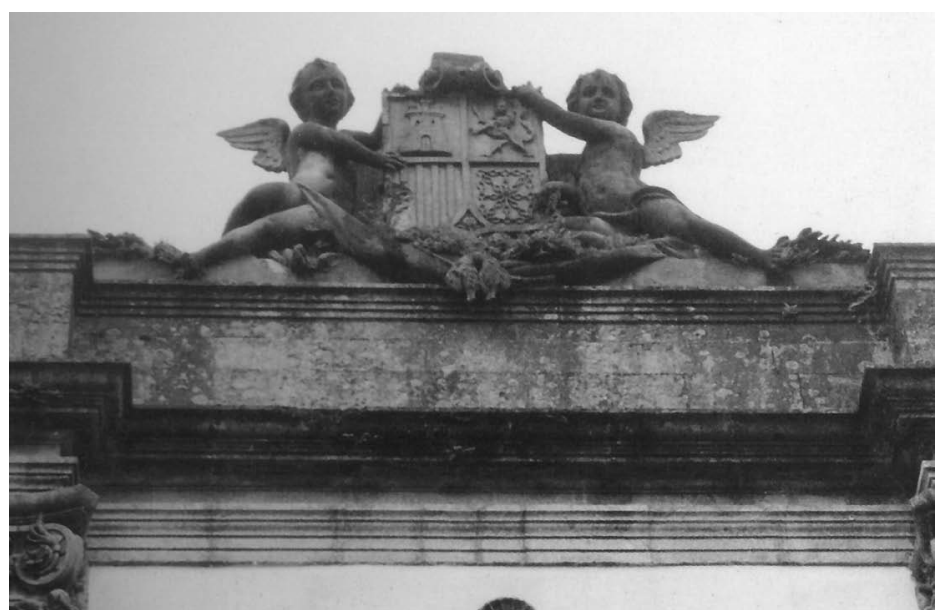

Fig. 12

Rafael de la Torre Mirón. Detalle del cuerpo principal. 1915. Col. Juan Rodríguez

${ }^{41}$ Como es lógico, no tenía mucho sentido que el escudo nacional presidiera la sede de la institución autonómica, por lo que fue suplantado tras la reforma de cuartel para Parlamento de Galicia. 
dían piezas de más volumen y peso del que se podía dominar a esa altura, y en otras era necesario recurrir al martillo pneumático ${ }^{42}$.

Tras un sucinto recorrido por la historia constructiva de la Escuela Veterinaria santiaguesa, parece ineludible constatar su deuda con el imperante gusto ecléctico, así como su filiación a los marcados criterios higienistas. Su construcción, no solo supuso la incorporación de una arquitectura, por entonces, novedosa y con visos de modernidad, sino que contribuyó decisivamente al desarrollo zonal de la Compostela extramuros, actuando como foco imantador y directriz del nuevo desarrollo urbano de la ciudad. Por consiguiente, acertaremos si consideramos a dicha escuela como uno de los pilares fundamentales sobre los que se ha sustentado el desarrollo del llamado Ensanche compostelano.

El Santiago finisecular, aun siendo una ciudad refractaria a la modernidad, introduce en su catálogo arquitectónico auténticas joyas del eclecticismo de época que, junto a la Escuela Veterinaria, consagrarán a la ciudad como indiscutible epicentro universitario. Me asalta como ejemplo, La reforma de la Universidad (1889) y La Escuela de Sordomudos y Ciegos (Actual Xunta de Galicia) (1925), ambas realizadas por Ricardo Velázquez Bosco, o la fastuosa Escuela Médica (1928) de Fernando Arbós. Todas ellas, irán definiendo a Compostela como centro incuestionable del saber gallego. Por descontado, tal empresa traerá consigo modificaciones urbanas de gran calado que incidirán tanto en la dilatación espacial de su callejero, como en la liberación tectónica de una ciudad, por tradición, medieval, organicista, y hermética.

42 REBOREDO SANTOS, Andrés, "O frontón da torre principal" en Concurso de anteproxectos para adaptación do cuartel do Hórreo para sede do parlamento de Galicia, Santiago de Compostela 1987, 66-8. 